\title{
SISTEM PENGAMAN PINTU MENGGUNAKAN SIDIK JARI DAN ANDROID
}

\author{
Jovi Saputra \\ Rizaldi \\ Salahuddin* \\ Widdha Mellyssa \\ Usmardi \\ Politeknik Negeri Lhokseumawe, Aceh
}

\begin{abstract}
Security is an important thing to pay attention to and to create that security, there are many things we can do, the most obvious common thing we do, for example to guard a house is to hire a security guard / house keeper. But to hire a house guard requires a fairly expensive cost. With the development of electronic technology, the security system is increasingly sophisticated and growing, so far there has often been theft or burglary from this house where a security door building system has been developed using fingerprint and Android as a controller. For this security door method using finger print and android as a door opener or controller. In this equipment, only the fingerprints that are registered on the finger print can access the door to open, and Android functions as a notification whether the door has been opened or not. Operationally, this security door system works well and is regulated by a microcontroller, and this system works well, with the data that we tested that this security door is $100 \%$ safe using the finger print method with the data we tested.
\end{abstract}

\section{Keywords:}

Fingerprint, Security, android, microcontroller, controller

\begin{abstract}
Abstrak
Keamanan merupakan suatu hal penting untuk diperhatikan dan untuk menciptakan keamaan itu banyak hal yang bisa kita lakukan, hal umum paling nyata yang kita lakukan misalnya untuk menjaga rumah ialah menyewa satpam/penjaga rumah. Tetapi untuk menyewa penjaga rumah memerlukan biaya yang lumayan mahal. Dengan berkembangnya teknologi elektronik, maka sistem keamanan semakin canggih dan berkembang, selama ini sering terjadi pencurian ataupun pembobolan rumah dari sinilah dikembangkan sistem bangun pengaman pintu menggunakan fingerprint dan android sebagai pengontrol. Untuk metode pintu keamanan ini menggunakan finger print dan android sebagai pembuka atau pengontrol pintu. Dalam peralatan ini hanya sidik jari yang terdaftar pada finger print yang bisa mengakses pintu untuk terbuka dan android berfungsi untuk sebagai pemberitahuan status pintu telah dibuka ataupun belum. Secara oprasional sistem pintu keamanan ini bekerja dengan baik dan diatur oleh mikrokontroler,dan sistem ini bekerja dengan baik, dengan data yang kami ujicoba yaitu pintu keamaan ini $100 \%$ aman dengan menggunakan metode finger print dengan data yang kami uji.
\end{abstract}

\section{Kata Kunci:}

Fingerprint, keamanan, android, mikrokontroler, pengontrol

DOI: $\underline{10.38038 / \text { vocatech.v2i1.32 }}$

Received: 24 July 2020 ; Accepted: 23 September 2020 ; Published: 15 October 2020

\section{*Corresponding author:}

Salahuddin, Program Studi Teknologi Elektronika, Jurusan Teknik Elektro, Politeknik Negeri Lhokseumawe, Jalan Banda Aceh - Medan, KM. 280,3, Buketrata, Lhokseumawe, Aceh, Indonesia.

Email: salahuddin.mt@pnl.ac.id 
Jovi Saputra, Rizaldi, Salahuddin, Widdha Mellyssa, Usmardi

\section{PENDAHULUAN}

Keamanan merupakan suatu hal penting untuk diperhatikan dan untuk menciptakan keamaan itu banyak hal yang bisa kita lakukan, hal umum paling nyata yang kita lakukan misalnya untuk menjaga rumah ialah menyewa satpam/penjaga rumah. Tetapi untuk menyewa penjaga rumah memerlukan biaya yang lumayan mahal, namun dengan perkembangan teknologi yang ada kita bisa dengan mudah memantau atau menjaga keadaan rumah dengan aman dan mudah. (Saputra, 2019)

Dari sinilah penerapan teknologi elektronika di perlukan untuk membuat keadaan keamanan rumah aman, adapun sistem yang dibuat ialah sistem keamanan sidik jari dan android, sistem kerja dari keamanan ini ialah seseorang harus menempelkan sidik jari nya untuk membuka pintu rumah, tetapi dengan syarat sidik jari harus sama dengan data yang telah tersimpan di sistem finger print dan mikrokontroler atau seseorang dapat membuka pintu rumah pintu rumah dengan menggunakan android dan android akan memeberitahukan keadaan status pintu, untuk membuka dari dalam terdapat tombol push button yang lebih efektif dalam membuka pintu. (Saputra, 2019)

Permasalahan yang yang timbul saat penelitian diantaranya bagaimana pengendalian dari rancang pintu pengaman ini dan mengetahui pengaman pintu menggunakan sidik jari (Fingerprint) dan smartphone android sebagai pengontrol berbasis mikrokontroler telah bekerja, serta pembacaan sidik jari dari sistem ini.

Tujuan dari penelitian ini adalah untuk mempermudah masyarakat luas untuk memantau keadaan rumah atau tempat yang perlu dilindungi agar tetap aman.

\section{STUDI PUSTAKA}

Tahun 2009 Jamaludin mahasiswa Politeknik Negeri Lhokseumawe pernah membuat tugas akhir berjudul "Rancang Pengaman Pintu Menggunakan RFID (radio frekuensi identifikasi) Berbasis Mikrokontroller" pada tugas akhir tersebut rancangan pintu pengaman hanya menggunakan RFID sebagai sensor yang digunakan untuk mengetahui objek, kekurangan alat ini tag RFID hanya dapat menginformasikan dalam jarak dekat. (Nazir, M., Jamaluddin, J., \& Muhaimin 2019)

Tahun 2014 Ai Fitri Silvia mahasiswa Universitas Pendidikan Indonesia pernah juga membuat tugas akhir yang berjudul "Rancang Bangun Akses Kontrol Pintu Gerbang Berbasis
Arduino dan Android' kelemahan dari alat ini ialah tidak bisa menggunakan multi user karena sifat bluetooth yang hanya satu arah saja. (Silvia, A. F., Haritman, E., \& Mulyadi 2014)

Pada penelitian ini penulis juga ingin membuat sebuah pengaman pintu yang berbeda yaitu "Rancang Bangun Pengaman Pintu Menggunakan Sidik Jari dan Android Sebagai Pengontrol Berbasis Mikrokontroller" alat ini penulis buat untuk bertujuan untuk mengontrol atau pun memantau keadaan rumah agar tetap aman, dan dengan berkembang nya teknologi, maka dalam pengaman pintu ini penulis menggunakan finger print sebagai sensor dan android sebagai pengaman pintu. Prinsip kerja dari pintu ini mempunyai dasar yang jelas berbeda, dengan menggunakan RFID pintu hanya terbuka dengan objek yang 6 diterima sedangkan dengan pintu pengamaan sidik jari dan android pintu pengaman ini lebih efektif dan dengan menggunakan sidik jari yang terdaftar maka pintu baru terbuka, ditambah dengan android mempunyai aplikasi yang bisa membuka pintu dari android memudahkan pengguna pintu keamanan ini untuk lebih cepat mengetahui bahwa pintu dibuka dan android bisa sebagai pembuka pintu ditambah push button juga bisa membuka pintu dari dalam. (Saputra, 2019)

Sidik jari (fingerprint) merupakan hasil reproduksi tapak jari baik yang sengaja diambil, dicapkan dengan tinta, maupun bekas yang ditinggalkan pada benda karena pernah tersentuh kulit telapak tangan atau kaki. Kulit telapak adalah kulit pada bagian telapak tangan mulai dari pangkal pergelangan sampai ke semua ujung jari, dan kulit bagian dari telapak kaki mulai dari tumit sampai ke ujung jari yang mana pada daerah tersebut terdapat garis halus menonjol yang keluar satu sama lain yang dipisahkan oleh celah atau alur yang membentuk struktur tertentu, yang mana sensor ini akan mengirim data ID sidik jari memalui komunikasi serial. Jenis sensor yang digunakan ialah optical atau optis (gambar 1) yang dimaksud optical ialah sensor ini bekerja dengan cara merekam pola dari sidik jari dengan menggunakan cahaya yang dipancarkan dari scanner. (Andrianto, 2008)

Alat pembaca sidik jari tersebut merupakan sebuah kamera yang mengeluarkan cahaya kemudian menangkap permukaan sidik jari dan pantulannya akan diberikan kepada alat penerima dan kemudian akan disalurkan ke dalam memori untuk disimpan di dalam template sebagai data 
Jovi Saputra, Rizaldi, Salahuddin, Widdha Mellyssa, Usmardi

utama. Kelebihan dari sensor ini adalah mudah untuk digunakan dengan biaya murah. Namun juga terdapat kelemahan dari sensor optis yaitu hasil dari scanning sangat tergantung dari kualitas sidik jari tersebut. Jika kualitas sidik jari jelek karena luka ataupun kotor, maka hasil dari pembacaaan proses identifikasi tidak akan baik.

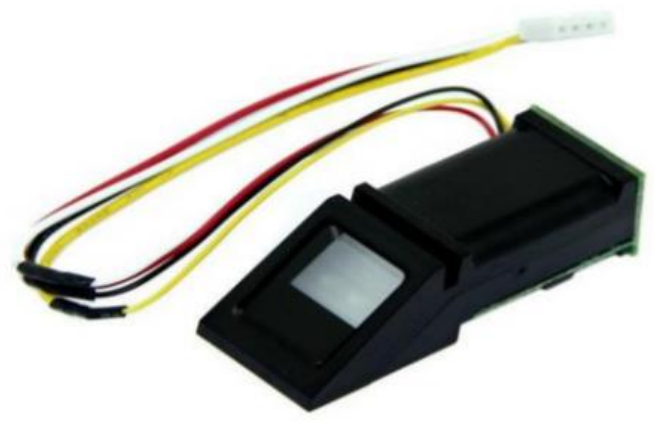

Gambar 1. Fingerprint

(Grove, n.d.)

\section{A. Sidik Jari}

Biometrik merupakan suatu metode komputerisasi yang menggunakan aspek-aspek biologi terutama karakteristik unik yang dimiliki oleh manusia. Karakterisitik fisiologi unik yang dapat digunakan adalah sidik jari (fingerprint) dan retina mata. Teknologi biometrik memiliki beberapa kelebihan seperti tidak mudah hilang, tidakbisa dipalsukan, dan tidak mudah rusak. Sistem pengenalan sidik jari untuk mengidentifikasi sidik jari seseorang sehingga mudah dikenali ciri unik dari seseorang tersebut.

Keunggulan biometrik adalah (Tumuli, Najoan, and Sambul 2017) :

1. Biometrik tidak akan hilang (fisik) atau lupa (perilaku) kecuali karena kecelakaan (trauma).

2. Biometrik tidak bisa ditiru ataupun juga diberikan ke orang lain. Biometrik mengharuskan orang yang bersangkutan ada ditempat dimana dilakukan identifikasi.

Adapun kelebihan dan kelemahannya sebagai berikut :

1. Mudah untuk digunakan

2. Sulit untuk diduplikasi

3. Memiliki keamanan yang tingkat keamanan yang cukup tinggi

Kelemahan yaitu :

a. Ancaman pada privasi seseorang karena dapat digunakan dan dikumpulkan tanpa diketahui seseorang misalnya pada CCTV di tempat umum.

b. Ancaman dari hacker c. Ancaman privasi yang disebabkan alat-alat dengan scanner data biometric dihack dan digunakan untuk mengumpulkan data biometric seseorang tanpa sepengetahuan orang tersebut.

Kendala utama dalam pengenalan sidik jari dengan metode berbasis minutiae pada umumnya citra sidik jari memiliki kualitas yang rendah, disebabkan oleh jenis kulit (berminyak, kering, dan cacat). Dalam kondisi lingkungan, jenis sidik jari dapat didefinisikan yaitu: sidik jari berminyak, sidik jari kering dan sidik jari netral. Salah satu cara yang dapat melakukan untuk proses peningkatan kualitas citra sidik jari yaitu dengan metode FFT (fast fourier transform). Penggunaan FFT ini didasarkan pada sifat sidik jari yang berubah-ubah (nonstationary) artinya karakteristik-karakteristik mempunyai nilai yang berbeda-beda pada satu bagian dengan bagian yang lain dalam sebuah citra sidik jari. (Salahuddin, 2012)

Sidik jari terdiri dari pola gunung interleaved (bagian yang naik ke atas) dan sebuah lembah (dips). Langkah pertama dalam pengenalan sidik jari biasanya melibatkan pengkategorian sidik jari menjadi satu dari lima kelas dasar, yang disebut kelas Henry terdiri dari Plain Arch, Tented Arch, Left Loop, Right Loop, dan Whorl. (Siswanto, Efendi, and Yulianti 2018)

Selain itu hanyalah variasi dari kombinasi keempat pola ini. Setiap orang mungkin saja memiliki Whorl, Arch, atau Loop di setiap ujung jari (sidik jari) yang berbeda, mungkin sebuah Triradius pada gunung dari Luna dan di bawah setiap jari, dan kebanyakan orang ada juga yang mempunyai dua Whorl atau Loop di tangan lainnya. Pola-pola dapat juga ditemukan pada ruas kedua dan ketiga di setiap jari.

\section{B. Whorl}

Whorl bisa berbentuk sebuah spiral, tipe sidik jari whorl yang berbentuk lingkaran di dalam lingkaran atau seperti lingkaran papan target panahan, sangat umum di dunia, termasuk Indonesia. Pemilik tipe sidik jari ini dinilai sangat bergantung pada logika. Orang dengan sidik jari ini juga melihat suatu pekerjaan dari tujuannya dan apakah bermaanfaat atau tidak untuk dirinya. 
Jovi Saputra, Rizaldi, Salahuddin, Widdha Mellyssa, Usmardi

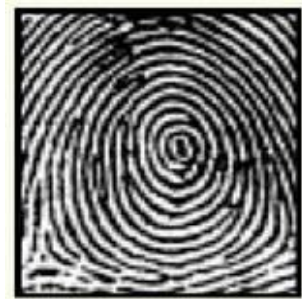

Plain Whorl

\section{Gambar 2. Pola Plain Whorl}

(wikimu.com 2012)

\section{Arch}

Dalam lengkungan, tonjolan jari berjalan terus menerus dari satu sisi jari ke sisi lainnya tanpa rekursi. Ada dua sub-kelompok yang selanjutnya mendefinisikan pola lengkung:

\section{A. Plain Arch}

Pola ini memiliki konsistensi aliran padanya. Ini dimulai di satu sisi jari, dan kemudian punggungan mengalir sedikit ke atas, hampir menyerupai gelombang di laut. Lengkungan polos adalah pola sidik jari yang paling sederhana untuk dilihat.

\section{B. Tented Arch}

Pola ini mirip dengan lengkungan polos yang dimulai dari satu sisi jari dan mengalir keluar dengan pola yang mirip ke sisi lainnya. Namun, perbedaan lengkungan tenda terletak pada punggungan di tengah, yang tidak kontinu seperti pada lengkungan biasa. Punggungan yang saling berdampingan di tengah menyatu dan menjorok ke atas, memberi kesan tenda yang bernada tinggi.

Perhatikan setiap pola arch menaik sangat tinggi.

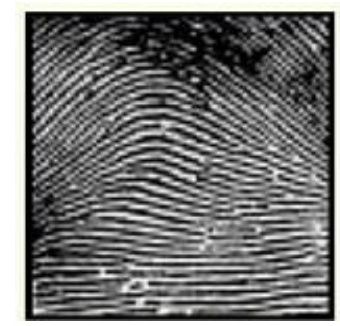

\section{Gambar 3. Pola Plain Arch}

(wikimu.com 2012)

\section{Loop}

Dalam loop, punggung bukit membuat belokan ke belakang tetapi tidak berputar. Putaran mundur, atau putaran, ini dibedakan berdasarkan bagaimana putaran mengalir di tangan dan bukan bagaimana alirannya pada kartu tempat jejak diambil. Jejak pada kartu sidik jari mirip dengan gambar terbalik yang kita lihat saat kita melihat diri kita di cermin. Ada dua sub kelompok yang diidentifikasi dalam kategori ini:

A. Loop Radial --- ini adalah loop yang mengalir menuju tulang jari-jari tangan atau, dengan kata lain, ketika kemiringan loop ke bawah dari arah jari kelingking menuju ibu jari tangan.

B. Ulnar Loop --- ini adalah loop yang mengalir ke arah tulang ulna tangan atau, dengan kata lain, ketika kemiringan ke bawah dari loop dari arah ibu jari ke arah jari kelingking tangan.

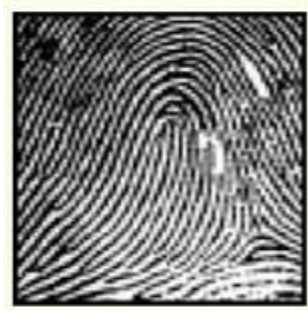

\section{Gambar 4. Pola Radial Loop}

(wikimu.com 2012)

\section{E. Android}

Android adalah sistem operasi dengan sumber terbuka, dan Google merilis kodenya di bawah lisensi apache. Kode dengan sumber terbuka dan lisensi perizinan pada android memungkinkan perangkat lunak untuk dimodifikasi secara bebas dan didistribusikan oleh para pembuat perangkat, operator nirkabel, dan pengembang aplikasi. Selain itu, android memiliki sejumlah besar komunitas pengembang aplikasi (apps) yang memperluas fungsionalitas perangkat.

Faktor-faktor di atas telah memberikan kontribusi terhadap perkembangan android, menjadikannya sebagai sistem operasi telepon pintar yang paling banyak digunakan di dunia, mengalahkan symbian pada tahun 2010. Android juga menjadi pilihan bagi perusahaan teknologi yang menginginkan sistem operasi berbiaya rendah, bisa dikustomisasi, dan ringan untuk perangkat berteknologi tinggi tanpa harus mengembangkannya dari awal. Sifat android yang terbuka juga telah mendorong munculnya sejumlah besar komunitas pengembang aplikasi untuk menggunakan kode sumber terbuka sebagai dasar proyek pembuatan aplikasi, dengan menambahkan fitur-fitur baru bagi pengguna 
Jovi Saputra, Rizaldi, Salahuddin, Widdha Mellyssa, Usmardi

tingkat lanjut atau mengoperasikan android pada perangkat yang secara resmi dirilis dengan menggunakan sistem operasi lain.

Ada juga yang mendefinisikan smartphone sebagai sebuah telephone genggam pintar yang memiliki fitur canggih seperti email, internet, pembaca ebook dan lainnya. Singkatnya, smartphone merupakan komputer kecil yang memiliki kemampuan sebuah telephone. (Tobing, 2014)

\section{F. Modul Wifi}

Modul wifi jaringan nirkabel merupakan komunikasi antar komputer (mesin) tanpa menggunakan kabel (Samsugi, Ardiansyah, and Kastutara 2018).

Jaringan nirkabel ini sering dipakai untuk jaringan komputer baik pada jarak yang dekat (beberapa meter, memakai alat/pemancar) maupun pada jarak jauh (lewat satelit). Jaringan nirkabel biasanya menghubungkan satu sistem komputer dengan sistem yang lain dengan menggunakan beberapa macam media transmisi tanpa kabel, seperti : gelombang radio, gelombang mikro, maupun cahaya infra merah. Jenis jaringan yang populer dalam kategori jaringan nirkabel ini meliputi : jaringan kawasan lokal nirkabel (wireles LAN/WLAN), dan Wi-Fi. Kelebihan umum :

1. Menghemat penggunaan kabel, yang bisa cukup mengganggu secara estetika, dan juga kerumitan installasi untuk menghubungkan lebih dari 2 piranti bersamaan.

2. Teknologi wireless memungkinkan suatu jaringan untuk bisa mencapai tempat - tempat yang tidak dapat dijangkau jaringan kabel.

3. Dapat menyediakan user dengan informasi access yang real-time, dimana saja dalam suatu organisasi. Mobilitas semacam ini sangat mendukung produktivitas dan peningkatan kualitas pelayanan apabila dibandingkan dengan jaringan kabel (Wicaksono, 2017).
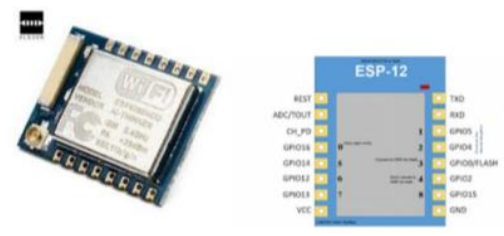

Gambar 5. Wifi Komponen

\section{METODE}

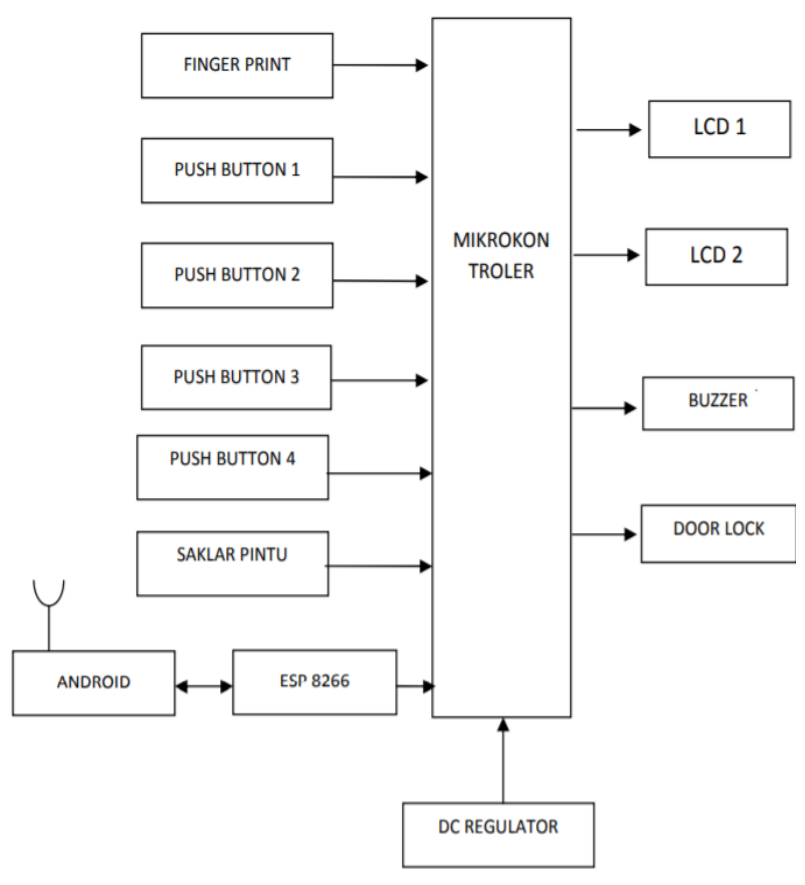

Gambar 6. Blok Diagram

Proses alur kerja sistem diharapkan mampu menjadikan sistem pengaman pintu yang dibuat dapat berjalan dengan baik. Alur kerja sistem yang dibuat sebagai garis besarnya saja untuk mempermudah dalam penulisan kode program dan pembuatan flowchart sistem nantinya. Sistem akan bekerja jika mikrokontroler telah mendapatkan supply tegangan dan arus.

Penjelesan input output seperti pada blok diagram pada gambar 6 susunan sistem input output terdiri dari :

a. Mikrokontroller berfungsi sebagai pusat pengontrolan saluran sistem rangkainan dan menyimpan program yang akan disesuaikan dengan keperluan tersebut.

b. Finger print berfungsi sebagai pengenalan sidik jari yang sudah terdaftar.

c. Push button berfungsi untuk sebagai tombol untuk membuka door lock dari dalam

d. Driver ic regulator berfungsi untuk menahan tegangan atau arus dari mikrokontroler

e. Buzzer berfungsi sebagai bunyi tanda bahwa finger print telah di terima dengan benar

f. Android berfungsi sebagai informasi ,dan pembuka pintu 24

g. Limit switch berfungsi sebagai pemutus dan penghubung arus saat pintu terbuka atau pun tertutup

h. Selenoid lock berfungsi sebagai membuka atau menutup pintu 
Jovi Saputra, Rizaldi, Salahuddin, Widdha Mellyssa, Usmardi

i. $\quad L C D$ berfungsi sebagai pemberitahuan secara digital bahwa id atau nama pengguna yang sudah terdaftar.

Pada dasarnya rancang pintu keamaan digunakan agar kita lebih mudah mengontrol keadaan rumah tetap aman dari keadaan dan terkendali, ini memudahkan kita sehingga menjadi lebih efektif dan efesien. Pintu keamanan menggunakan sidik jari ini di rancang agar tidak ada orang yang bisa membuka pintu keamanan selain si pengguna sidik jari yang telah terdaftar terlebih dahulu di finger print, pertama tombol push button di tekan sebagai untuk mendaftar kan sidik jari dan $L C D$ berfungsi untuk memberitahukan ID pengguna yang sudah terdaftar, setelah itu meletakan sidik jari yang terdaftar di finger print, finger print akan membaca dalam satu detik sekali dan mengirim nya ke memori, setelah itu buzer berbunyi sekali tanda bahwa finger print di terima, dan door lock akan terbuka jika semua sistem bekerja dengan benar. (Kho, 2019)

Rangkaian modul wifi jaringan nirkabel adalah komunikasi antar sistem komputer tanpa menggunakan perantara kabel. Jaringan nirkabel ini sering dipakai untuk jaringan komputer baik pada jarak yang dekat (beberapa meter, memakai alat/pemancar) maupun pada jarak jauh (lewat satelit). Jaringan nirkabel biasanya menghubungkan satu sistem komputer dengan sistem yang lain dengan menggunakan beberapa macam media transmisi tanpa kabel, seperti : gelombang radio, gelombang mikro, maupun cahaya infra merah. Jenis jaringan yang populer dalam kategori jaringan nirkabel ini meliputi : jaringan kawasan lokal nirkabel (wireles LAN/WLAN), dan Wi-Fi. Gambar schematic wifi sebagai berikut.

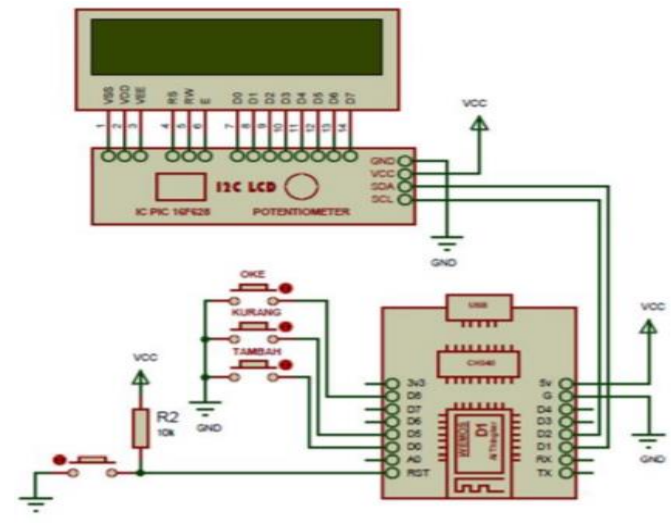

Gambar 7. Rangkaian Schematic Wifi

\section{HASIL DAN PEMBAHASAN}

Pengujian sistem merupakan data hasil pengujian sistem fingerprint. Pengujian menggunakan 10 user, yaitu 5 user terdaftar dan 5 user tidak terdaftar. User yang terdaftar memiliki ID yaitu; ID 6, ID 9, ID 12, ID 17, dan ID 32. Sementara user tidak terdaftar diberi nama Unknown 1, Unknown 2, Unknown 3, Unknow 4,dan Unknown 5.

Hasil pengujian terhadap 5 user terdaftar dinyatakan berhasil, terlihat dari keterangan kolom pembacaan fingerprint yaitu terbaca. Dan juga pengujian terhadap 5 user yang tidak terdaftar dinyatakan berhasil, Karna terlihat dari kolom pembacaan fingerprint yaitu tidak terbaca.

Tabel 2 Merupakan data hasil pengujian pengiriman data android. Pengujian ini dilakukan sebanyak 5 kali percobaan pengiriman data dari android ke IOT yang ada di alat.

Dari hasil pengujian sebanyak 5 kali dinyatakan berhasil, terlihat dari kolom pengiriman data yaitu terkirim semua, dan untuk waktu pengiriman data bisa dilihat di kolom waktu dengan waktu rata-rata 2,0 menit, cepat atau lambat pengiriman datanya tergantung dari faktor tertimbal nya program di IOT dan faktor jaringan.

Tabel 1. Pengujian Fingerprint

\begin{tabular}{|c|c|c|c|c|}
\hline No & User & $\begin{array}{l}\text { Pembacaan } \\
\text { Finger print }\end{array}$ & $\begin{array}{l}\text { Waktu } \\
\text { terbaca }\end{array}$ & $\begin{array}{l}\text { Tampil di } \\
\text { LCD } 2\end{array}$ \\
\hline 1 & ID 32 & Terbaca & $5.12 \mathrm{~s}$ & $\begin{array}{c}\text { \#ID } 32 \text { buka } \\
\text { pintu }\end{array}$ \\
\hline 2 & ID 6 & Terbaca & $4.92 \mathrm{~s}$ & $\begin{array}{l}\text { \#ID } 6 \text { buka } \\
\text { pintu }\end{array}$ \\
\hline 3 & ID 9 & Terbaca & $4.43 \mathrm{~s}$ & $\begin{array}{c}\text { \#ID } 9 \text { buka } \\
\text { pintu }\end{array}$ \\
\hline 4 & ID 12 & Terbaca & $3.32 \mathrm{~s}$ & $\begin{array}{c}\text { \#ID } 12 \text { buka } \\
\text { pintu }\end{array}$ \\
\hline 5 & ID 17 & Terbaca & 4.53 & $\begin{array}{c}\text { \#ID } 17 \text { buka } \\
\text { pintu }\end{array}$ \\
\hline 6 & $\begin{array}{l}\text { Unkno } \\
\text { wn } 1\end{array}$ & $\begin{array}{l}\text { Tidak } \\
\text { terbaca }\end{array}$ & $3.07 \mathrm{~s}$ & $\begin{array}{l}\text { Finger not } \\
\text { fond }\end{array}$ \\
\hline 7 & $\begin{array}{l}\text { Unkno } \\
\text { wn } 2\end{array}$ & $\begin{array}{l}\text { Tidak } \\
\text { terbaca }\end{array}$ & $8.00 \mathrm{~s}$ & $\begin{array}{l}\text { Finger not } \\
\text { fond }\end{array}$ \\
\hline 8 & $\begin{array}{l}\text { Unkno } \\
\text { wn } 3\end{array}$ & $\begin{array}{l}\text { Tidak } \\
\text { terbaca }\end{array}$ & $5.00 \mathrm{~s}$ & $\begin{array}{l}\text { Finger not } \\
\text { fond }\end{array}$ \\
\hline 9 & $\begin{array}{l}\text { Unkno } \\
\text { wn } 4\end{array}$ & $\begin{array}{l}\text { Tidak } \\
\text { terbaca }\end{array}$ & $8.11 \mathrm{~s}$ & $\begin{array}{l}\text { Finger not } \\
\text { fond }\end{array}$ \\
\hline
\end{tabular}


Jovi Saputra, Rizaldi, Salahuddin, Widdha Mellyssa, Usmardi

\begin{tabular}{ccccc}
\hline 10 & $\begin{array}{c}\text { Unkno } \\
\text { wn 5 }\end{array}$ & $\begin{array}{c}\text { Tidak } \\
\text { terbaca }\end{array}$ & $3.15 \mathrm{~s}$ & $\begin{array}{c}\text { Finger not } \\
\text { fond }\end{array}$ \\
\hline
\end{tabular}

Tingkat keberhasilan $=\frac{\text { Jumlah keberhasilan }}{\text { Jumlah pengujian }} \times 100 \%$

$$
\begin{aligned}
& =\frac{10}{10} \times 100 \% \\
& =100 \% \text { keberhasilan }
\end{aligned}
$$

Pembacaan Fingerprint $=$

$5,12+4,92+4,43+3,32+4,53+3.07+8.00+5.00+8.11+3.15$

$$
=4.9 \mathrm{~s}
$$

Rata-rata waktu membuat pintu terbuka $=4.9 \mathrm{~s}$

Tabel 2. Pengujian pengiriman data android

\begin{tabular}{llll} 
No & Percobaan & $\begin{array}{c}\text { Pengiriman } \\
\text { data }\end{array}$ & Waktu \\
\hline 1 & Perc 1 & Terkirim & $1.0 \mathrm{~m}$ \\
\hline 2 & Perc 2 & Terkirim & $1.3 \mathrm{~m}$ \\
\hline 3 & Perc 3 & Terkirim & $2.0 \mathrm{~m}$ \\
\hline 4 & Perc 4 & Terkirim & $2.0 \mathrm{~m}$ \\
\hline 5 & Perc 5 & Terkirim & $2.5 \mathrm{~m}$ \\
\hline
\end{tabular}

Tingkat Keberhasilan $=\frac{\text { Jumlah keberhasilan }}{\text { Jumlah percobaan }} \times 100 \%$ $=\frac{5}{5} \times 100 \%=100 \%$ keberhasilan

Rata-rata waktu=

Jumlah waktu percobaan yang berhasil

Jumlah percobaan

$=\frac{1 \mathrm{~m}+1.3 \mathrm{~m}+2 \mathrm{~m}+2 \mathrm{~m}+2.5 \mathrm{~m}}{5}=1,3$ menit rata - rata

\section{KESIMPULAN DAN SARAN}

\section{A. Kesimpulan}

Berdasarkan hasil pengujian dan analisis pada sistem pintu pengaman berbasis mikrokontroller, maka dapat diambil beberapa kesimpulan diantaranya pengontrol yang digunakan adalah Atmega162 sebagai inti dari keseluruhan sistem, pembacaan sensor fingerprint dapat berfungsi dengan baik, android berfungsi sebagai pembuka pintu dan pengontrol status pintu serta Push button Memiliki fungsi sebagai pembuka pintu dan juga untuk mendaftar ID Sidik jari baru.

\section{B. Saran}

Untuk kesempurnaan hasil penelitian, kami memberikan saran di antaranya : Selain menggunakan finger print sistem pintu pengaman dapat juga diganti dengan sensor pembaca wajah, kemudian akan lebih bagus jika di pintu di pasang motor biar pintu bisa terbuka otomatis, dan juga akan lebih bagus jika pada sistem pintu pengaman ini menggunakan wifi ataupun kartu data yang mempunyai sinyal yang baik dan stabil agar sistem bekerja dengan lancar.

\section{REFERENSI}

Andrianto, Heri. 2008. "Pemrograman Mikrokontroler AVR ATmega16 Menggunakan Bahasa C (CodeVision Avr)." Informatika, Bandung.

Grove. n.d. "Fingerprint Sensor." Https://Wiki.Seeedstudio.Com/.

Kho, Dickson. 2019. "Pengertian LCD (Liquid Crystal Display) Dan Prinsip Kerja LCD." Https://Teknikelektronika.Com/PengertianLcd-Liquid-Crystal-Display-Prinsip-KerjaLcd/. 2019.

Nazir, M., Jamaluddin, J., \& Muhaimin, M. 2019. "Rancang Bangun Sistem Pengaman Pintu Rumah Menggunakan Kode Password Dan Smartphone Berbasis Mikrokontroler." Jurnal Mahasiswa Teknik Elektro 1 (1): 3035.

Salahuddin, Tulus, Fahmi. 2012. "Peningkatan Kualitas Citra Sidik Jari Menggunakan Fft (Fast Fourier Transform)." Jurnal Litek (ISSN: 1693-8097) 9 (2): 74-78.

Samsugi, Selamet, Ardiansyah Ardiansyah, and Dyan Kastutara. 2018. "Arduino Dan Modul Wifi ESP8266 Sebagai Media Kendali Jarak Jauh Dengan Antarmuka Berbasis Android." Jurnal Teknoinfo 12 (1): 23. https://doi.org/10.33365/jti.v12i1.42.

Saputra, Jovi. 2019. "RANCANG BANGUN PENGAMAN PINTU MENGGUNAKAN SIDIK JARI DAN ANDROID SEBAGAI PENGONTROL (HARDWARE)." Politeknik Negeri Lhokseumawe.

Silvia, A. F., Haritman, E., \& Mulyadi, Y. 2014. "Rancang Bangun Akses Kontrol Pintu Gerbang Berbasis Arduino Dan Android." Electrans, UPI 13 (1): 1-10.

Siswanto, Apri, Akmar Efendi, and Ana Yulianti. 2018. "Alat Kontrol Akses Pintu Rumah Dengan Teknologi Sidik Jari Di Lingkungan Rumah Pintar Dengan Data Yang Di Enkripsi." Jurnal Penelitian Pos Dan $\begin{array}{llll}\text { Informatika } \quad 8 & \text { (2): } 97 .\end{array}$ https://doi.org/10.17933/jppi.2018.080201.

Tobing, S. L. 2014. "Rancang Bangun Pengaman Pintu Menggunakan Sidik Jari (Fingerprint) 
Jovi Saputra, Rizaldi, Salahuddin, Widdha Mellyssa, Usmardi

Dan Smartphone Android Berbasis Mikrokontroler Atmega8." Doctoral dissertation, Tanjungpura University.

Tumuli, Andika D.L., Xaverius B. N. Najoan, and Alwin Sambul. 2017. "Implementasi Teknologi Biometrical Identification Untuk Login Hotspot." Jurnal Teknik Informatika 12 (1): $1-5$. https://doi.org/10.35793/jti.12.1.2017.17873.

Wicaksono, M. Fajar. 2017. "Implementasi Modul Wifi NodeMCU ESP8266 Untuk Smart Home." Jurnal Teknik Komputer Unikom 6 (1): $1-6$.

wikimu.com. 2012. "4 Pola Dasar Sidik Jari Dan

Kepribadian Manusia.” Http://Sidik-

Jari.Com/. 2012. 